\title{
Impaired thymopoiesis occurring during the thymic involution of tumor-bearing mice is associated with a down-regulation of the antiapoptotic proteins $\mathrm{Bcl}-\mathrm{X}_{\mathrm{L}}$ and $\mathrm{A1}$
}

\author{
ROBERTO CARRIO and DIANA M. LOPEZ \\ Department of Microbiology and Immunology, Miller School of Medicine, University of Miami, Miami, FL 33136, USA
}

Received September 11, 2008; Accepted October 6, 2008

DOI: $10.3892 /$ ijmm_00000105

\begin{abstract}
The thymus is a central lymphoid organ in which $\mathrm{T}$ lymphocytes undergo differentiation and maturation without the need for antigenic stimulation. Apoptosis (programmed cell death), plays a critical role in shaping the $\mathrm{T}$ cell repertoire, deleting unproductive as well as potentially autoreactive $\mathrm{T}$ cells. Thymic atrophy has been observed in several model systems, including aging, graft-vs-host-disease and tumor development. However, the mechanisms involved in this phenomenon remain to be completely elucidated. We have previously shown that the progressive growth of D1-DMBA-3 mammary tumor leads to extreme thymic atrophy in the host. This thymic involution is associated with an early block in $\mathrm{T}$ cell maturation at the triple negative stage of differentiation. In the present study we have used our murine mammary tumor model to further analyze the specific $\mathrm{T}$ cell subpopulations present in the thymus of tumor-bearing animals as well as to characterize the alterations of the apoptotic process present during the impaired thymopoiesis associated to this thymic involution. Flow cytometric analysis revealed a moderate increase in the percentages of single positive $\mathrm{CD}^{+}$and $\mathrm{CD}^{+}$cells within the $\mathrm{CD} 3$ negative population in the thymuses of tumor-bearing mice. Moreover, we observed a prolonged increase in apoptosis among thymocytes from tumor-bearing mice compared with thymocytes from normal mice during tumor development. Lastly, we found a major decrease of Bcl- $\mathrm{X}_{\mathrm{L}}$ and $\mathrm{A} 1$, two crucial anti-apoptotic Bcl-2 family members that are developmentally regulated in $\mathrm{T}$ cells. Together, our data suggest that the severe thymic involution seen in mammary tumor bearers is due to an arrest in at least
\end{abstract}

Correspondence to: Professor Diana M. Lopez, Department of Microbiology and Immunology, Miller School of Medicine, University of Miami, P.O Box 016960, Miami, FL 33101, USA

E-mail: dlopez@med.miami.edu

Abbreviations: NM, normal mice; TBM, tumor-bearing mice

Key words: tumor-bearing mice, thymic involution, apoptosis, $\mathrm{Bcl}-\mathrm{X}_{\mathrm{L}}, \mathrm{A} 1$ two steps of $\mathrm{T}$ cell differentiation and a down-regulation of important molecules that control programmed cell death.

\section{Introduction}

The thymus is a specialized organ that is critical for the development and maintenance of an effective peripheral $\mathrm{T}$ cell repertoire $(1,2)$. The development of $\alpha \beta^{+}$TCR T cells in the thymus encompasses a progressive stepwise differentiation from a multi-potent precursor, producing a mature thymocyte with defined potential function (3). The earliest precursors of the $\mathrm{T}$ cell pathway in the adult thymus are CD3-CD4-CD8progenitors, a population which has been further subdivided on the basis of expression of CD44 and CD25, with the most immature stage identified as $\mathrm{CD} 44^{+} \mathrm{CD} 25^{-}(4,5)$. Differentiation and commitment to the thymocyte lineage is associated with expression of CD25 and loss of CD44 (6). The cells become $\mathrm{CD} 44^{+} \mathrm{CD} 25^{+}$then $\mathrm{CD} 44-\mathrm{CD} 25^{+}$and during this period there is a rearrangement of the $\beta$-chain of the $\mathrm{T}$ cell receptor (TCR) and subsequent expression of this chain at the cell surface with a TCR $\alpha$-chain equivalent (the pre-T $\alpha$-chain) (7). The $\beta$-chain then pairs with the pre TCR $\alpha$-chain and members of the CD3 complex to form the pre-TCR (8). A loss of CD25 expression and a period of selection before the cell becomes an immature thymocyte $\left(\mathrm{CD} 3{ }^{-} \mathrm{CD} 4{ }^{+} \mathrm{CD} 8^{+}\right)$occur when there is rearrangement and expression of the TCR $\alpha$-chain. The pre-TCR signals in a ligand-independent manner and induce the phosphorylation of the $\mathrm{CD} 3$ to develop the $\mathrm{CD} 3{ }^{+} \mathrm{CD} 4{ }^{+} \mathrm{CD} 8{ }^{+}$ thymocytes population (9). It is in this stage when the TCR $\alpha$ chain undergoes rearrangement after which there is TCR $\alpha \beta$ dependent selection (10). Many of these double positive cells fail to mature further, but a small percentage develop into mature thymocytes expressing either CD4 or CD8 alone before they can leave the thymus to enter the periphery (11).

Apoptosis plays an essential role in maintaining cellular homeostasis during $\mathrm{T}$ cell development and differentiation (12). In the immune system, recent investigations revealed that during the course of T-cell development in the thymus, negative selection of autoreactive immature T-cells is a typical apoptotic process (13). Two major pathways lead to apoptosis: the intrinsic cell death pathway controlled by Bcl-2 family members and the extrinsic cell death pathway controlled by death receptor signaling (14). These two pathways work together to regulate $\mathrm{T}$ lymphocyte development and function. 
The Bcl-2 family consists of proteins which share sequence homology within conserved regions known as Bcl-2 homology (BH) domains $(15,16)$. Members of this family are among

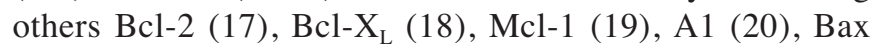
(21), Bak (22), Bad (23), Bik (24), Bid (25), Bcl-w (26) hrk (27), Mtd (28), Diva (29), and PUMA (30). Interestingly, whereas some of these members such as Bcl- $\mathrm{X}_{\mathrm{L}}, \mathrm{Mcl}-1$, A1 and $\mathrm{Bcl}-\mathrm{w}$ are, like Bcl-2, potent inhibitors of cell death, others like Bax, Bak, Bad, Bik, Bid, hrk, Mtd, Diva and PUMA promote programmed cell death at least in part by counteracting the protective effect of Bcl-2 or Bcl- $\mathrm{X}_{\mathrm{L}}(31,32)$. Mice deficient in Bcl-2 exhibit normal maturation of both $\mathrm{B}$ and $\mathrm{T}$ cell lineages, indicating that $\mathrm{Bcl}-2$ is not essential for lymphoid development $(33,34)$. In contrast, in vivo overexpression of $\mathrm{Bcl}-2$ and/or $\mathrm{Bcl}-\mathrm{X}_{\mathrm{L}}$ in developing $\mathrm{B}$ cells interferes with normal induction of cell death and promotes autoimmune manifestations (35). However, several groups have demonstrated that $\mathrm{Bcl}-\mathrm{X}_{\mathrm{L}}$ and $\mathrm{A} 1$ are developmentally regulated in T lymphocytes (36-39).

In healthy individuals, the thymus is most active in early life, with the novo production of $\mathrm{T}$ cells gradually declining with increasing age (2). Atrophy in the thymus has been identified as one of the key events that precede inefficient functioning of the immune system and an irreversible, inevitable age-related deterioration process of this organ $(40,41)$. Although thymic atrophy has been observed in several model systems, including graft-vs-host-disease (GVHD) and tumor development (42), the mechanisms involved in this phenomenon remains to be completely elucidated.

Using a murine mammary adenocarcinoma originally induced in BALB/c mice by dimethylbenzanthracene (D1DMBA-3) (43), we have previously described a profound progressive thymic atrophy associated with the tumor development (44). This thymic involution is accompanied by a decrease in total cell number paralleled by a dramatic decrease in the percentages of $\mathrm{CD} 4^{+} \mathrm{CD} 8^{+}$thymocytes and an increase in the percentage of $\mathrm{CD} 4^{+} \mathrm{CD} 8^{-}$and $\mathrm{CD} 4{ }^{-} \mathrm{CD} 8^{+}$ single positive population an CD4-CD8- double negative population (45). We have investigated several possible mechanisms leading to this thymic atrophy. The findings of those investigations suggest that the thymic hypocellularity seen in mice with an advanced stage of mammary tumor progression is not due to a decreased level of in vivo proliferation, but correlates with an arrest of thymic differentiation at an early stage accompanied by a minor increase in apoptosis (46). Moreover, we have shown that there is an extensive disruption of the thymic architecture that begins to be apparent two weeks following tumor implantation (44).

In the present study we have examined other possible mechanisms that characterize this thymic atrophy. Importantly, our data strongly suggest that, in addition to the previously described arrest of thymocytes at the triple negative stage of differentiation, in thymuses of tumor-bearing mice a second blockage may be occurring at the level of immature single positive populations. Moreover, we showed that apoptosis appears to be gradually increased in thymocytes during early tumorigenesis, mostly due to a down-regulation of the antiapoptotic proteins $\mathrm{Bcl}-\mathrm{X}_{\mathrm{L}}$ and $\mathrm{A} 1$. Collectively, we suggest that both arrests in the normal $\mathrm{T}$ cell development and an increase in apoptosis could be major causes for the impaired thymopoiesis seen during the thymic involution of tumorbearing mice.

\section{Materials and methods}

Mice and tumor. Male and female BALB/c mice were bred and housed under barrier conditions in the Division of Veterinary Resources at the University of Miami, Miller School of Medicine. Ten to 14 weeks-old mice were used for tumor transplantation. The tumor is a transplantable mammary adenocarcinoma, called D1-DMBA-3, derived from a nonviral, non-carcinogen-induced preneoplastic alveolar nodule in a BALB/c mouse treated with 7,12-dimethylbenzanthracene (43). The immunogenic D1-DMBA-3 tumor is routinely transplanted in $\mathrm{BALB} / \mathrm{c}$ mice by s.c. injection of $1 \times 10^{6}$ tumor cells. Palpable tumor is apparent $\sim 8$ days following implantation and the mice normally die between 4 and 6 weeks after tumor inoculation. Our institutional animal care and use committee approved the animal experiments.

Thymocytes collection. Mice were sacrificed and both lobes of the thymus were carefully dissected from the chest cavity and placed in a Petri dish containing 1X Hanks' balanced salt solution, $1 \%$ calf serum, $10 \mathrm{mM}$ HEPES, $\mathrm{pH} 7.2$, to prevent drying. The thymic lobes were weighed and placed in a cell strainer in a Petri dish with a drop of medium on the top, and gently compressed with the base of a 3-ml syringe followed by a wash with cold media and transfer to polypropylene tubes. Cells were counted and analyzed by flow cytometry as described below.

Flow cytometry. The following antibodies were used for flow cytometry and purchased from BD Pharmingen (San Diego, CA): Pacific blue anti-CD3 (500A2), APC anti CD4 (RM4-5) and Per-CP anti-CD8 (53-6.7). The cells were analyzed using a BD Biosciences LSRII Cytometer (BD Biosciences, San Jose, CA) and Diva software (BD Biosciences). The total number of events collected for analysis was between 100,000 and 500,000 cells.

Annexin $V$ analysis. To determine apoptosis, cells were analyzed over time by staining phosphatidylserine translocation with FITC-annexin V (Pharmingen) according to the manufacturer's instructions.

$m R N A$ analysis. For semi-quantitative RT-PCR analysis, total RNA was extracted from the entire thymus of normal and tumor-bearing mice with TRIzol (Life Technologies, Grand Island, NY) using a tissue homogenizer from OMNI International (Marietta, GA). cDNA was prepared from this total RNA and the following mouse primers (5'-3') were used for PCR: 5'-CCGGAGAGCGTTCAGTGATC-3', 5'-TCAG GAACCAGCGGTTGAAG-3' for the Bcl-X $\mathrm{X}_{\mathrm{L}}$ gene, 5'-GCCC TGGATGTATGTGCTTAC-3', 5'-GATCTGTCCTGTCATC TGCAG-3' for the A1 gene and 5'-AGCCATGTACG TAGCCATCC-3', 5'-TGTGGTGGTGAAGCTGTAGC-3' for the $B$-actin gene (47). The conditions were $20,24,28$ or 32 cycles of extension, $0.5 \mathrm{~min}$ at $94^{\circ} \mathrm{C}$ for denaturation, $1 \mathrm{~min}$ at $55^{\circ} \mathrm{C}$ for annealing and $1 \mathrm{~min}$ at $72^{\circ} \mathrm{C}$ and then a final cycle of $10 \mathrm{~min}$ at $72^{\circ} \mathrm{C}$. PCR products were visualized after 
A)

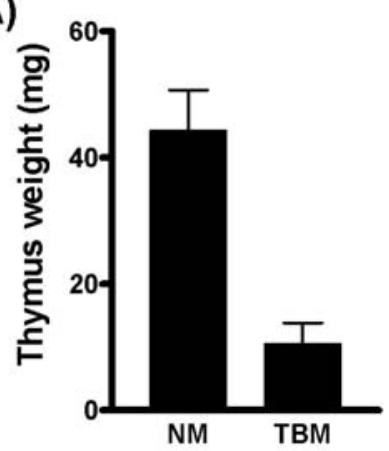

B)

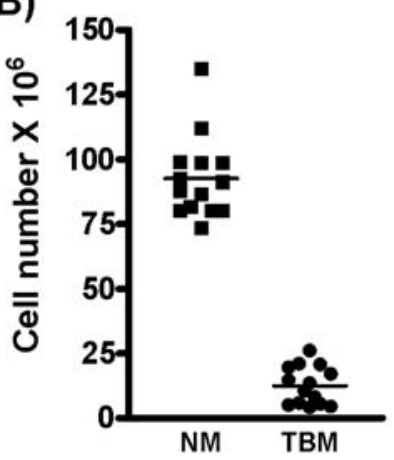

C)
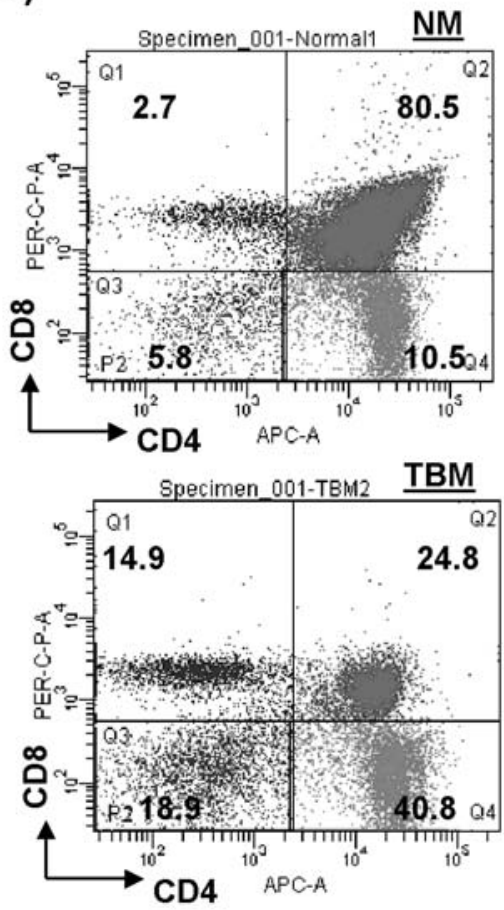

Figure 1. Thymic involution and phenotype caused by tumor implantation. Mice were injected with D1-DMBA-3 tumor as described in Materials and methods and were analyzed 3.5 weeks after tumor injection. (A) Thymus weight and (B) cell number in tumor-bearing mice (TBM) were compared to normal mice (NM). (C) Thymocytes from the different mice were stained with antibodies against anti-CD4 and anti-CD8 to compare their phenotypes by flow cytometry. Data represent the mean \pm SD (A and B) of three independent experiments each with 3-4 animals per group or representative (C) of three different experiments.

electrophoresis through $1.5 \%$ agarose gels by staining with ethidium bromide. For GeneArray Analysis, Mouse JAK/ STAT Signaling Pathway GeneArray systems were purchased from SuperArray Bioscience Corp. (Frederick, MD). Total thymic RNA was obtained from the different mice as described above, the cDNA was prepared from this total RNA and hybridized to the arrayed filters according to the manufacturer's instructions. The resulting hybridization signal was visualized by chemiluminescence. Data were subjected to densitometric analysis using Scion Image Software (Scion, Frederick, MD). RNA levels were expressed as relative OD measurement after normalizing to the hybridization signals to GAPDH or $ß$-actin as previously described (48).

Western blot analysis. Whole cell extracts of thymuses from normal and tumor-bearing mice were used. The thymuses were lysed using cold RIPA assay buffer supplemented with protease inhibitor cocktail tablets (Roche, Indianapolis, IN) and sodium vanadate (Roche, $1 \mathrm{mmol} / \mathrm{l}$ final concentration). Protein concentration was determined using the BCA Protein Assay kit (Pierce, Rockford, IL) before analyzing the samples by Western blotting. The primary antibodies used were a goat polyclonal antibody anti-A1 (clone T-18) from Santa Cruz Biotechnology (Santa Cruz, CA) and a rabbit anti-Bcl- $\mathrm{X}_{\mathrm{L}}$ polyclonal antibody (49) (a gift from Dr Lawrence H. Boise). The presence of $\beta$-actin was detected by the use of a rabbit antimouse polyclonal antibody (Sigma-Aldrich). The secondary antibodies used were a peroxidase-conjugated donkey antigoat IgG from Santa Cruz Biotechnology for A1 and a goat anti-rabbit IgG from Jackson Immuno Research (West Grove, $\mathrm{PA}$ ) for Bcl- $\mathrm{X}_{\mathrm{L}}$ and $\mathrm{B}$-actin.
Proliferation assays. To measure antigen-driven proliferation, isolated total thymocytes $\left(5 \times 10^{5}\right.$ cells/well $)$ were cultured in $0.2 \mathrm{ml}$ of RPMI-1640 containing $5 \%$ FCS, glutamine $(30 \mu \mathrm{g} / \mathrm{ml})$, penicillin $(100 \mathrm{U} / \mathrm{ml})$, streptomycin $(100 \mu \mathrm{g} / \mathrm{ml})$, 2-ME $\left(5 \times 10^{-5} \mathrm{M}\right)(\mathrm{CM})$ in 96-well flat-bottom culture plates (3595; Costar, Cambridge, MA) with anti-CD3 (1 $\mu \mathrm{g} / \mathrm{ml})$ and IL-2 or IL-7 (10 ng/ml; Peprotech, Inc., Rocky Hill, NJ) for $48 \mathrm{~h}$. To measure cytokine-dependent proliferation, thymocytes activated with anti-CD3 and IL-2 were harvested, washed three times with RPMI-1640, and $2 \times 10^{4}$ cells/well were cultured in $0.2 \mathrm{ml}$ of CM in the presence of IL-2, IL-7 or IL-15 (all cytokines $10 \mathrm{ng} / \mathrm{ml}$ ) in 96-well flat-bottom culture plates for two additional days. In all cases, proliferation was measured by the addition during the last $4 \mathrm{~h}$ of $1 \mu \mathrm{Ci} /$ well of $\left[{ }^{3} \mathrm{H}\right]$-thymidine $(25 \mathrm{Ci} / \mathrm{mmol}$; Amersham, Arlington Heights, IL).

\section{Results}

As we have shown previously, the growth of D1-DMBA-3 mammary tumor leads to extreme thymic atrophy in the host (44) which have been associated with an early stage block in $\mathrm{T}$ cell maturation of the triple negative thymocytes (46). During the tumor development, there is a major decrease in the thymus weight and cell numbers in thymuses of tumorbearing mice as compared to those from normal mice (NM) (Fig. 1A and B). The decrease in total cell number is paralleled by a dramatic decrease in the percentages of double positive $\mathrm{CD} 4^{+} \mathrm{CD} 8^{+}$thymocytes and an increase in the percentages of $\mathrm{CD}^{+}{ }^{+} \mathrm{CD} 8{ }^{-}$and $\mathrm{CD} 4{ }^{-} \mathrm{CD} 8^{+}$single populations and double negative CD4-CD8- thymocytes in tumor-bearing mice 
A)

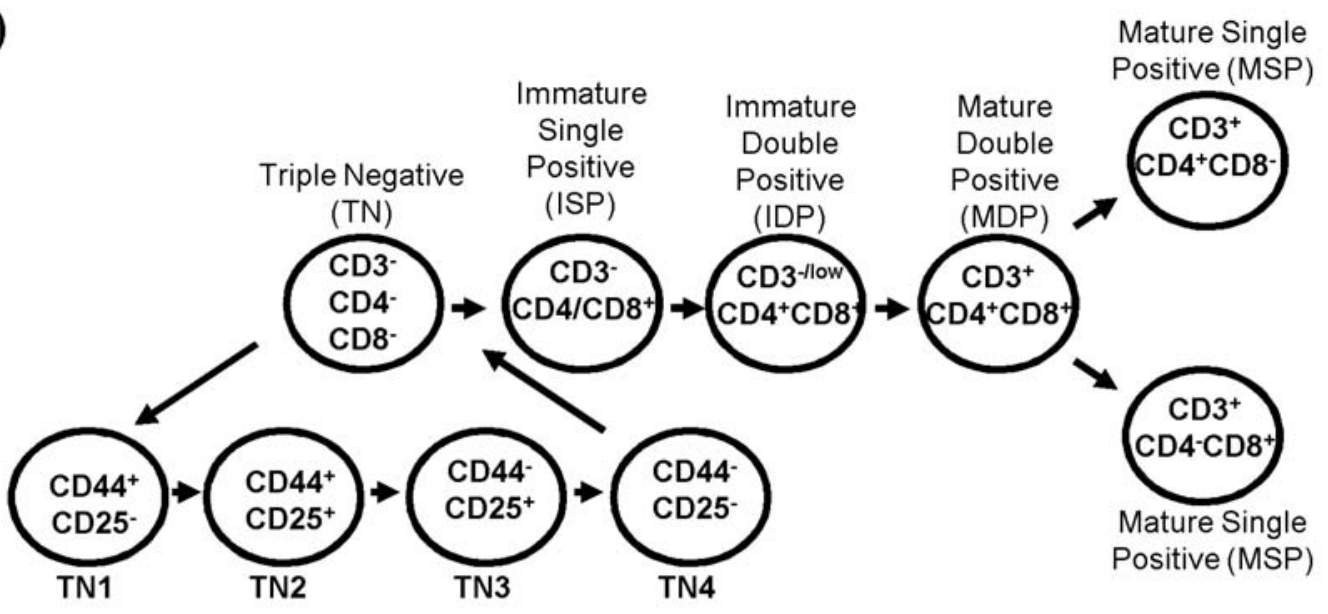

B)

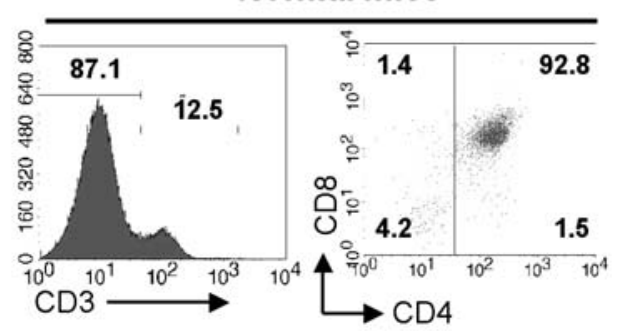

C)

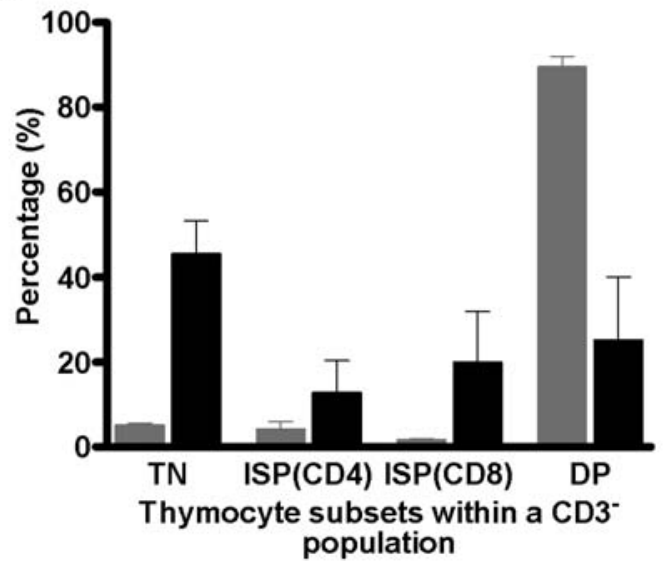

Tumor-bearing mice

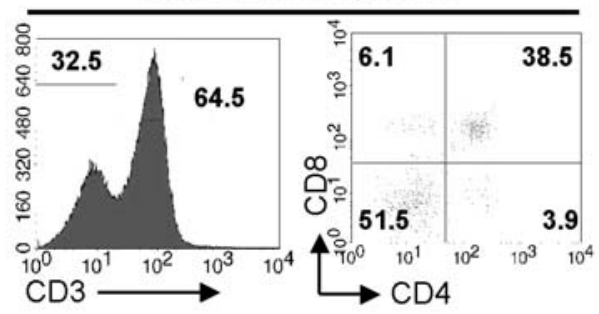

D)

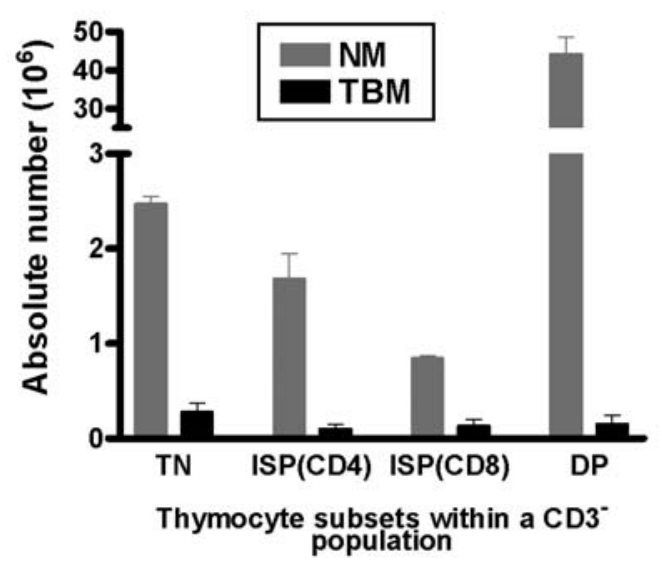

Figure 2. CD3- single positive $\mathrm{CD}^{+}$and $\mathrm{CD}^{+}$thymocytes are arrested at immature stage of the T development in the thymuses of tumor bearers. Mice were injected with D1-DMBA-3 tumor and were analyzed as described in Fig. 1. (A) Schematic representation of T-cell development in the thymus from a normal mouse. (B) Thymocytes from the different mice were stained with antibodies against CD3, CD4 and CD8 as described in Materials and methods. Thymocytes were selected on the CD3-negative populations, and the CD4 and CD8 staining profiles within this population are displayed. Percentages (C) and absolute numbers (D) from the different thymocyte populations gated within the CD3-negative population. Data are representative (B) or the mean \pm SD (C and D) of three independent experiments each with 3 animals per group.

(Fig. 1C). To further characterize the alterations leading to the involution present in the thymuses of tumor-bearing mice, a more detailed evaluation of thymic differentiation in tumor-bearing mice was undertaken. To this end, we first focused on the immature single positive thymocytes within the CD3-negative population (Fig. 2A). As shown in Fig. 2B, there is a profound decrease in the percentage of CD3-negative thymocytes in tumor bearers $(32.5 \%)$ as compared to those from normal mice $(87.1 \%)$. While there is an increase in the relative percentage of triple negative thymocytes in tumor bearers (Fig. 2C), their absolute number is greatly diminished
(Fig. 2D). Furthermore, thymuses from tumor bearers have a greatly reduced percentage of $\mathrm{CD} 4{ }^{+} \mathrm{CD} 8^{+}$cells within the CD3-negative population (immature double positive cells, Fig. 2B and C) in comparison to the levels in normal thymuses (38.5\% versus $92.8 \%$ ). The percentage of single positive $\mathrm{CD}^{+}{ }^{+}$or $\mathrm{CD}^{+}$cells within the $\mathrm{CD} 3$ negative population also showed moderate increases in the thymuses of tumor-bearing mice (Fig. 2B and C). Importantly, the absolute numbers of these two populations were diminished in tumor bearers' thymuses (Fig. 2D). These results suggest that in addition to the previously described arrest of thymocytes at the triple 
A)

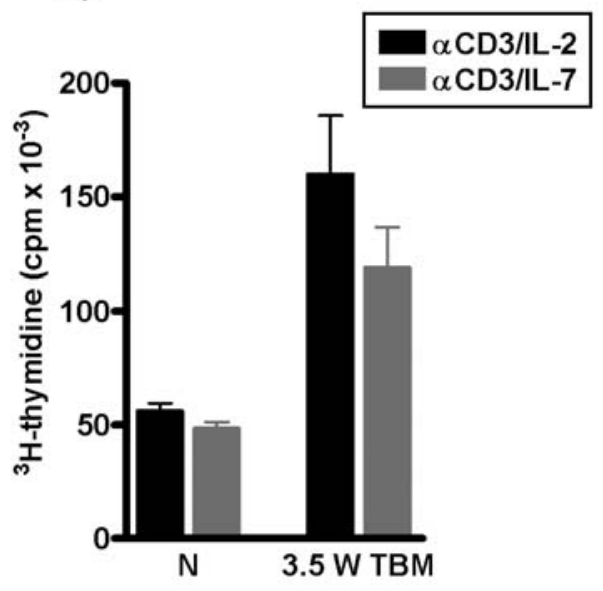

B)

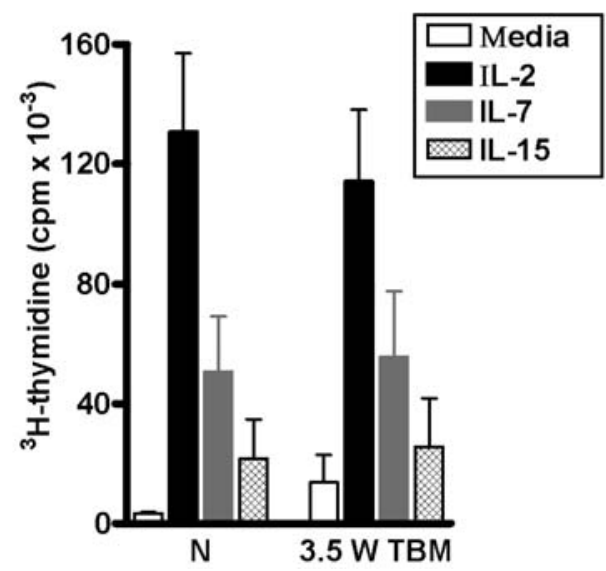

Figure 3. Impaired T cell development present in thymuses of tumor-bearing mice is not associated with a decreased level of in vitro $\mathrm{T}$ cell proliferation. Mice were injected with D1-DMBA-3 tumor and thymocytes from normal and tumor-bearing mice were collected as described in Materials and methods. (A) Thymocytes from normal and tumor-bearing mice were activated in vitro in the presence of anti-CD3 and IL-2 or IL-7. (B) Thymocytes activated with anti-CD3 and IL-2 were washed and further cultured in vitro in the presence of IL-2, IL-7 or IL-15. In both cases proliferations were assessed 48 h latter $\left[{ }^{3} \mathrm{H}\right]$-thymidine incorporation as described in Materials and methods. Data are mean $\pm \mathrm{SD}$ of three independent experiments.

negative stage of differentiation (46), in thymuses of tumorbearing mice, a second block may be occurring at the level of immature single positive populations.

Normal levels of in vitro proliferation of mature thymocytes from tumor-bearing animals. In previous studies we have demonstrated that the in vivo proliferation of total and CD4-CD8- thymocytes is unaffected by the presence of the tumor (46). In the current study, to investigate whether the accumulation of single positive $\mathrm{CD}^{+}{ }^{+} \mathrm{CD} 8{ }^{-}$and $\mathrm{CD} 4{ }^{-} \mathrm{CD} 8^{+}$ populations present in the thymuses of tumor bearers occurs because of an augmented proliferative capacity of these cells, thymocytes from normal and tumor-bearing mice were activated in vitro in the presence of anti-CD3. We also evaluated the functionality, on mature thymocytes, of the different cytokine receptors which promote proliferation.

Thymocytes from normal and tumor-bearing mice were activated in vitro during $48 \mathrm{~h}$ in the presence of anti-CD3 and the indicated cytokines. As shown in Fig. 3A, thymocytes from tumor-bearing mice displayed a strong proliferative response when compared to thymocytes from normal mice. To determine whether this major proliferative response in thymocytes from tumor-bearing mice could be related more to the presence of a major number of mature thymocytes in these thymuses than an altered function, in vitro activated thymocytes from normal mice and tumor-bearing mice were washed, and the same cell number were recultured in the presence of IL-2, IL-7 or IL-15. As shown in Fig. 3B, the proliferative properties of thymocytes from tumor-bearing mice were very similar to those from normal mice. Moreover, thymocytes from tumor-bearing mice showed similar responses to the different cytokines to those observed in thymocytes from normal mice. Collectively, these data suggest that the accumulation of single positive $\mathrm{CD}^{+}{ }^{+} \mathrm{CD} 8$-and $\mathrm{CD} 4{ }^{-} \mathrm{CD} 8^{+}$ populations present in the thymuses of tumor bearers is not due to an increase in the proliferative properties of these cells.
Prolonged increases in apoptosis among thymocytes from tumor-bearing mice compared with thymocytes from normal mice during tumor development. T cell development is regulated by an array of cellular processes that include proliferation, differentiation, and cell death. Under normal physiological conditions, apoptosis serves to ensure the selection of appropriate lymphoid populations during thymic development and to dampen the immune response in peripheral tissues. In previous studies we have shown a modest increase in apoptosis in thymocytes from mice 3 weeks after tumor implantation compared to thymocytes from normal mice (46). However, thymocytes from tumor-bearing mice treated with methylprednisolone were more susceptible to apoptosis induction than those from normal mice (46). To investigate whether the impaired $\mathrm{T}$ cell population observed in the thymuses of tumor-bearing mice could be associated with a gradual increase in apoptosis during the tumor development, we used the annexin V staining method. As shown in Fig. 4A, the thymus involution associated to tumor progression is linked to a gradual decrease in the percentage of double positive $\mathrm{CD}^{+}{ }^{+} \mathrm{CD} 8^{+}$population, in parallel with a gradual increase in the percentages of single positive $\mathrm{CD} 4{ }^{+} \mathrm{CD} 8$ and $\mathrm{CD}_{4} \mathrm{CD}^{+}$, and double negative $\mathrm{CD} 4 \mathrm{CD} 8^{-}$populations. When thymocytes from tumor-bearing mice from 2, 3 and 4 weeks after tumor inoculation were incubated in the presence of Annexin V (Fig. 4B), continuous increase in the total thymic cells positive for Annexin $\mathrm{V}$ were observed in the thymocytes during the tumor development. As seen in Fig. 4B, thymocytes from 2-week tumor-bearing animals showed similar levels of annexin $\mathrm{V}$ positive cells to those from normal mice. In contrast, the levels of total thymic cells positive for annexin $\mathrm{V}$ in thymocytes from 3 and 4 weeks tumor-bearing mice were expanded through tumor development. Moreover, when the thymic cells positive for annexin $\mathrm{V}$ were analyzed by flow cytometry, the majority were $\mathrm{CD} 4^{+} \mathrm{CD} 8^{+}$cells (data not shown). These data suggest that the impaired $\mathrm{T}$ cell development present in the thymuses of tumor-bearing 
A)
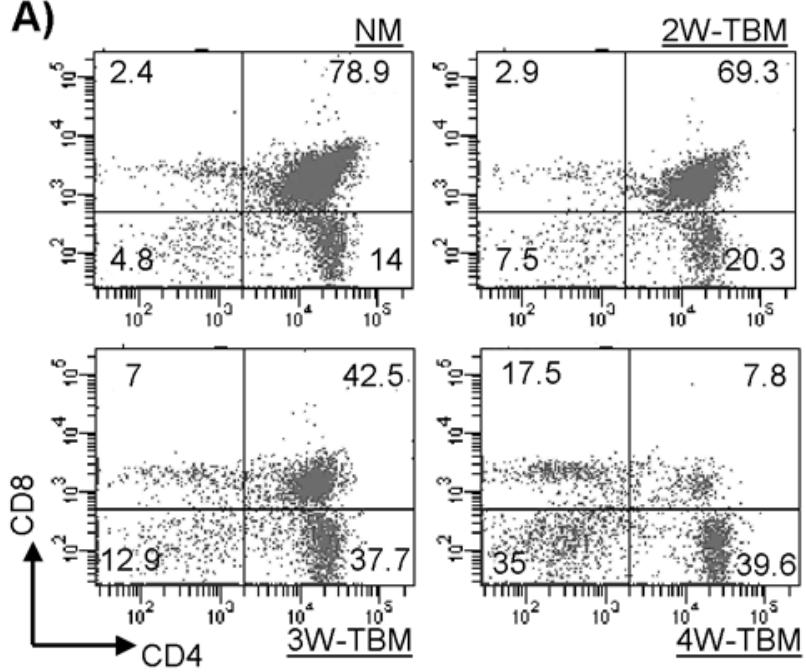

B)
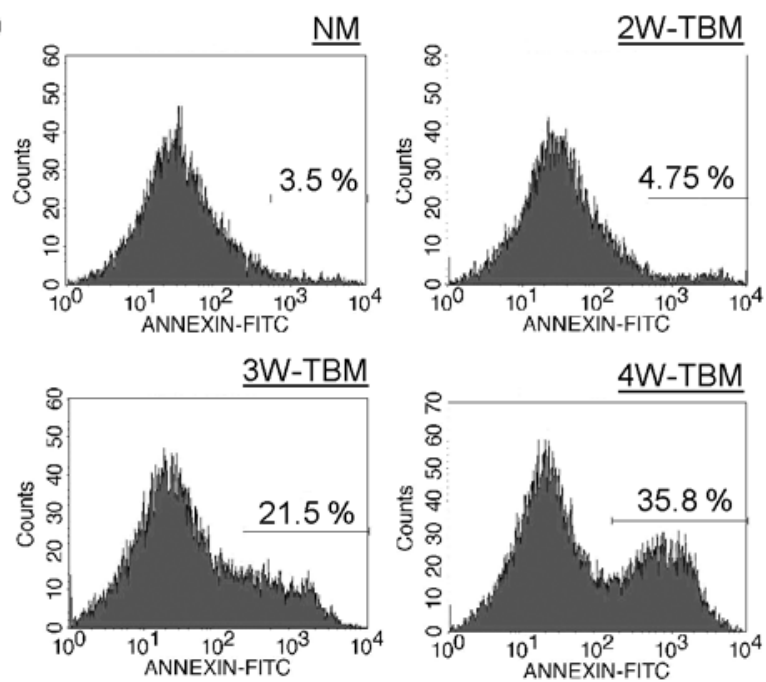

Figure 4. Thymic atrophy in tumor-bearing mice is associated with a gradual increase in apoptosis, especially among mature double positive thymocytes Mice were injected with D1-DMBA-3 tumor as described in Materials and methods and thymocytes were collected 2, 3 and 4 weeks after tumor implantation. (A) Thymocytes from normal and 2-, 3- and 4-week-tumorbearing mice were staining with antibodies against CD4 and CD8 and analyzed by flow cytometry. (B) Total population of thymocytes from the different mice were stained with Annexin V and analyzed by flow cytometry as described in Materials and methods. Data are representative of three independent experiments.

mice could be more related to damage in the apoptotic process that normally takes place during the thymocyte development, than impairment in the proliferative properties of these cells.

Down-regulation of the antiapoptotic gene $B c l-X_{L}$ and $A 1$ in the impaired $T$ cell development present in the thymuses of tumorbearing mice. To further investigate the apoptosis occurring in the lymphocytes during the tumor development, we analyzed the expression of several members of the Bcl-2 family members, molecules that suppress the apoptotic mechanisms. We evaluated the expression of the antiapoptotic proteins Bcl-2, Bcl- $\mathrm{X}_{\mathrm{L}}$ and A1 by semi-quantitative RT-PCR. These antiapoptotic proteins were selected because they have been
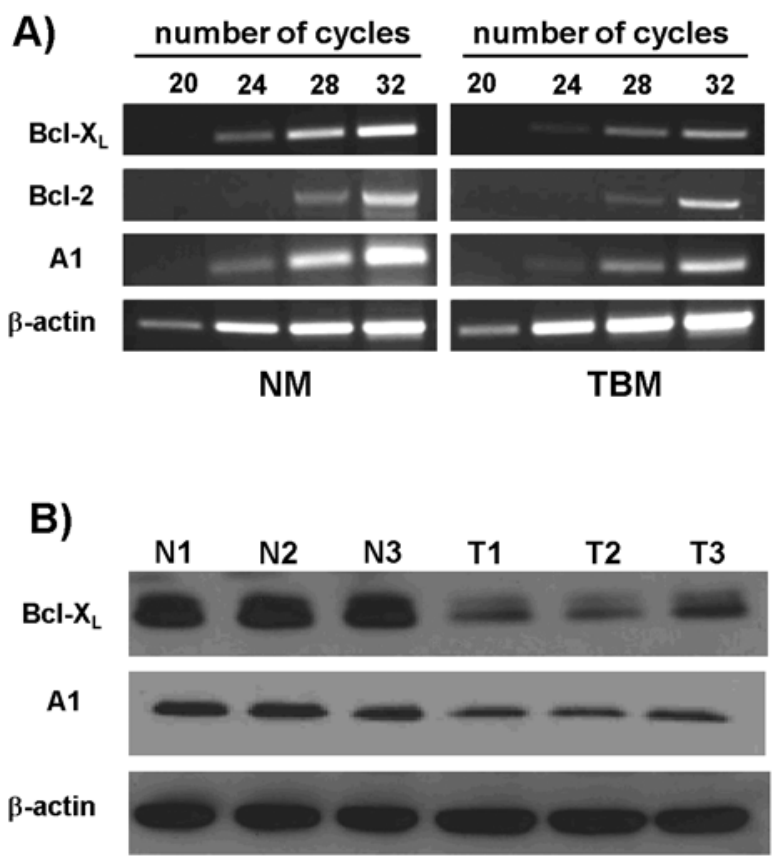

Figure 5. Impaired thymopoiesis observed in the thymuses of tumor-bearing mice is associated with a down-regulation of anti-apoptotic proteins involved in the normal $\mathrm{T}$ cell development. Mice were injected with D1-DMBA-3 tumor as described in Materials and methods and thymocytes were collected 3.5 weeks after tumor implantation. (A) Semi-quantitative expression of the Bcl- $\mathrm{X}_{\mathrm{L}}, \mathrm{Bcl}-2$ and A1 RNAs were analyzed in the thymocytes from normal and 3.5-week-tumor-bearing mice. (B) The protein levels of $\mathrm{Bcl}-\mathrm{X}_{\mathrm{L}}$ and $\mathrm{A} 1$ expression were assessed by Western blot analysis of thymuses from three normal mice (N1, N2 and N3) and three tumor-bearing mice (TBM1, TBM2 and TBM3). Data are representative of three independent experiments.

shown to have highly restricted cellular distribution within the thymus $(36,38,47,50)$. As shown in Fig. 5A, the levels of mRNA of Bcl-2, Bcl- $\mathrm{X}_{\mathrm{L}}$ and $\mathrm{A} 1$ detected by semi-quantitative analysis are down-regulated in the thymuses of tumor-bearing mice as compared to the levels in thymuses of normal mice. As shown previously by other investigators $(36,39)$, the expression of $\mathrm{Bcl}-\mathrm{X}_{\mathrm{L}}$ and $\mathrm{A} 1$ are specifically enhanced in the double positive thymocytes suggesting that both genes might be considered as a transcriptional signature of thymocytes that have received TCR survival signal. To corroborate the data obtained by RT-PCR for Bcl- $\mathrm{X}_{\mathrm{L}}$ and A1, a Western blot analysis using the thymuses of three normal and three tumorbearing mice were performed. As can be seen in Fig. 5B, the expression of $\mathrm{Bcl}-\mathrm{X}_{\mathrm{L}}$ and $\mathrm{A} 1$ in tumor-bearer thymuses is also down-regulated at the protein level in comparison to the levels observed in thymuses from normal mice. These data suggest that the diminished levels of $\mathrm{Bcl}-\mathrm{X}_{\mathrm{L}}$ and $\mathrm{A} 1$ may be playing a role in the decrease in the percentages of double positive $\mathrm{CD}^{+}{ }^{+} \mathrm{CD} 8{ }^{+}$thymocytes and leading to the impaired $\mathrm{T}$ cell development occurring during the thymic involution of tumor-bearing mice.

Thymic atrophy in tumor-bearing mice is associated with an impaired expression of molecules that regulate numerous aspects of hematopoiesis. In recent unpublished data from our laboratory, using thymuses from normal and tumorbearing mice, we observed that thymic involution present in 
Table I. Impaired expression of molecules that regulates numerous aspects of hematopoiesis.

\begin{tabular}{|c|c|c|}
\hline Gene symbol & Gene name & Fold change \\
\hline \multicolumn{3}{|c|}{ Genes down-regulated } \\
\hline \multicolumn{3}{|c|}{ in tumor-bearing mice } \\
\hline CBP & CREB binding protein & 5.7 \\
\hline Fas & Tumor necrosis factor receptor superfamily, member 6 & 4.6 \\
\hline Ghr & Growth hormone receptor & 4.8 \\
\hline Hmga1 & High mobility group AT-hook 1 & 3.2 \\
\hline Mcmd5 (Cdc46) & Mini chromosome maintenance deficient 5 & 28.6 \\
\hline NCoA1 & Mus musculus nuclear receptor coactivator 1 & 3.4 \\
\hline Pias1 & Protein inhibitor of activated STAT 1 & 3.6 \\
\hline Socs7 & Suppressor of cytokine signaling 7 & 13.9 \\
\hline Sp1 & Trans-acting transcription factor 1 & 3.6 \\
\hline \multicolumn{3}{|c|}{$\begin{array}{l}\text { Genes up-regulated } \\
\text { in tumor-bearing mice }\end{array}$} \\
\hline C-myc & Myelocytomatosis oncogene & 4.3 \\
\hline Cyclin D1 & Cyclin D1 & 3.5 \\
\hline EpoR & Erythropoietin receptor & 7.6 \\
\hline $\mathrm{IFN} \gamma$ & Interferon $\gamma$ & 3.2 \\
\hline Mmp3 & Mus musculus matrix metalloproteinase 3 & 5.7 \\
\hline Mpl & Myeloproliferative leukemia virus oncogene & 4.5 \\
\hline $\operatorname{Sosc} 2$ & Suppressor of cytokine signaling 2 & 4.9 \\
\hline Stat6 & Signal transducer and activator of transcription 6 & 3.5 \\
\hline
\end{tabular}

the thymuses of tumor-bearing mice is associated with a down-regulation of crucial cytokines involved in thymocyte development and cellular homeostasis. Cytokines regulate numerous aspects of hematopoiesis and the immune response via activation of the JAK/STAT pathway. To identify other transcription factors or molecules involved in the impaired $\mathrm{T}$ cell development occurring during the thymic involution of tumor-bearing mice, we analyzed the expression of mRNAs from the JAK/STAT signaling pathway in whole thymuses of normal and tumor-bearing mice using gene expression array analysis. Microarray analysis of the mRNAs related to different molecules controlling cell cycle or apoptosis revealed that 17 mRNAs were differentially expressed by at least 3-fold (Table I). Nine of the differentially expressed mRNAs were coordinately down-regulated in thymuses from tumor-bearing mice. When compared to thymuses from normal mice CBP, Fas, Ghr, Hmga1, Mcmd5, NCoA1, Pias1, Socs 1 and the transcription factor Sp1 were decreased in the thymuses of tumor-bearing mice. However, eight mRNAs, c-myc, Cyclin D1, EpoR, IFN $\gamma$, Mmp3, Mpl, Socs2 and Stat6 were increased in the thymuses of tumor-bearing mice when compared to the levels in thymuses of normal mice. These molecular changes support the notion that the impaired $\mathrm{T}$ cell development occurring during the thymic involution of tumor-bearing mice is at least in part due to the impaired apoptotic mechanisms induced by the down-regulation of the crucial cytokines involved in thymocytes development and cellular homeostasis.

\section{Discussion}

Like all hematopoietic cells, T lymphocytes are derived from bone-marrow-resident stem cells. However, whereas most blood lineages are generated within the marrow, the majority of $\mathrm{T}$ cell development occurs in a specialized organ, the thymus (51). Here, immature progenitor cells are guided through the differentiation and selection steps required to generate a T-cell repertoire that is both self-tolerant and has a propensity to bind self major histocompatibility complex components (52). These processes depend on an array of functionally distinct epithelial cell types within the thymic stroma, which have a common developmental origin in the pharyngeal endoderm (53). There has been long-standing interest in unraveling the cellular and molecular basis of thymus organogenesis. Thymic involution has been observed in several model systems, including aging, graft-versus-host disease, and tumor development, however, the mechanisms involved in this phenomenon remain to be elucidated.

We have reported that the thymic involution observed in D1-DMBA-3 mammary tumor-bearing mice is linked to an impaired thymopoiesis which is mainly associated with an early block in $\mathrm{T}$ cell maturation at the triple negative stage of differentiation $(45,46)$. Furthermore, we have shown that there is an extensive disruption of the thymic architecture that begins to be apparent two weeks following tumor implantation (44). The normal thymic stroma consists of two functional compartments known as the cortex and the medulla that are 
important for the positive selection of immature thymocytes and the deletion of self-reactive $\mathrm{T}$ cell clones, respectively. The thymic stromal cells have been shown to provide growth factors, cytokines, and extracellular matrix necessary for T-cell development (53). Our previous studies suggest that thymic stromal cells from tumor-bearers may not produce the necessary cytokines for appropriate $\mathrm{T}$ cell development. In this report we have shown that thymuses from tumor bearers have a greatly reduced percentage of $\mathrm{CD} 4^{+} \mathrm{CD} 8^{+}$cells within the CD3-negative population (immature double positive cells) in comparison to the levels in normal thymuses. These results indicate that in addition to the previously described arrest of thymocytes at the triple negative stage of differentiation (46), in thymuses of tumor-bearing mice, a second block occurs at the level of immature single positive populations.

In our published studies we analyzed two other possible mechanisms of atrophy in the thymuses of tumor-bearing mice i.e. a decrease in proliferation of thymocytes and an increase in the apoptosis of these lymphocytes (46). Regarding the first possibility we found that the in vivo proliferation of total and CD3-CD4-CD8- thymocytes appeared to be unaffected by the presence of the tumor. Thus, similar levels of in situ proliferation were detected in these thymic cells from either normal mice or tumor bearers, using in vivo labeling with BrdU. We further explored the possibility that abnormalities in proliferation could be detected after in vitro activation using $\left[{ }^{3} \mathrm{H}\right]$-thymidine incorporation. To this aim we activated thymocytes from normal and tumor-bearing mice with $\alpha \mathrm{CD} 3$ and IL-2 and further expanded them with IL-2, IL-7 or IL-15. These experiments revealed that no defects in the proliferative activity of tumor-bearer thymocytes are apparent nor there are alterations of the receptors for these cytokines in the thymocytes of tumor-bearing mice.

Regarding the second possibility of altered apoptosis in the thymuses of tumor bearers, our original study revealed a moderate increase of this function in animals with advanced stages of tumorigenesis (46). It has been extensively reported that apoptosis regulates the development of thymocytes, the shaping of $\mathrm{T}$ cell repertoire, its selection and the coordinate events leading to immune responses in the periphery (54). As we mentioned above, the two major pathways leading to apoptosis in the thymus are the pathway controlled by Bcl-2 family members and the pathway controlled by death receptor signaling. Although recent evidence suggest that Bcl-2 plays a role in positive selection in the thymus, its ability to influence negative selection in the thymus is controversial mainly because mice deficient in $\mathrm{Bcl}-2$ exhibit normal maturation of both $\mathrm{B}$ and $\mathrm{T}$ lineages, indicating that $\mathrm{Bcl}-2$ is not essential for lymphoid development $(33,34)$. A plausible explanation is that proteins other than $\mathrm{Bcl}-2$ can function as survival signals during the selection and maintenance of $\mathrm{T}$ lymphocytes. In this regard, other anti-apoptotic proteins such as $\mathrm{Bcl}-\mathrm{X}_{\mathrm{L}}$ and $\mathrm{A} 1$ have been shown to be developmentally regulated in $\mathrm{T}$ cells $(37,38)$. Bcl- $\mathrm{X}_{\mathrm{L}}$ was identified as the major Bcl-X mRNA form expressed during murine development that functions as a dominant regulator of apoptotic cell death $(18,55)$. A major role for Bcl- $\mathrm{X}_{\mathrm{L}}$ in thymocyte development was demonstrated in chimeric mice that are deficient in Bcl- $\mathrm{X}_{\mathrm{L}}$. In these studies, the absence of Bcl- $\mathrm{X}_{\mathrm{L}}$ preferentially affected immature populations of thymocytes and pre-B cells
(56). Moreover, Bcl- $\mathrm{X}_{\mathrm{L}}$ have been shown to provide a survival signal for the maintenance of more immature CD3-CD4 ${ }^{+} \mathrm{CD} 8^{+}$ thymocytes before positive selection (36). A1 was described as an early-response gene, expressed in several hematopoietic cell lineages, including T-helper lymphocytes, macrophages, and neutrophils $(20,57)$. In addition, A1 was demonstrated to have a restricted tissue distribution during embryonic development and functions to protect against cell death $(47,58)$. More recently, Verschelde and colleagues demonstrated that overexpression of A1 promotes the survival of double positive thymocytes awaiting positive selection (39). Since we have observed a decrease in the double positive $\mathrm{CD} 4^{+} \mathrm{CD} 8^{+}$thymic population of tumor bearers, we investigated whether changes had occurred in the expression of $\mathrm{Bcl}-\mathrm{X}_{\mathrm{L}}$ and $\mathrm{A} 1$ at the protein level. Our results revealed that indeed, there is a profound down-regulation of these two anti-apoptotic molecules in the thymuses of tumor-bearing mice in comparison to the levels expressed in thymuses of normal mice. Based on the present findings, a mechanistic scheme could be proposed in which the lower percentage of double positive $\mathrm{CD} 4^{+} \mathrm{CD} 8^{+}$thymocytes observed in tumor-bearing mice is due to a down-regulation of these anti-apoptotic proteins in these cells. It has been well supported previously that, the ratio of death antagonists to agonists determines whether a cell will respond to an apoptotic signal (59-61). An alternative nonexclusive interpretation is that other pro-apoptotic members of the Bcl-2 family could be expressed at high levels at this stage forming heterodimers with the anti-apoptotic proteins and this interaction promotes the programmed cell death. For instance, some pro-apoptotic members of the Bcl-2 family such as Bax have been shown to heterodimerize with Bcl- $\mathrm{X}_{\mathrm{L}}$ and A1 $(60,62)$. Previously, we have reported that the mammary tumor cells used in our studies secrete several factors that have effects in various compartments of the immune system (63-67). It could be argued that an impaired function of the stromal cell microenvironment could induce the expression of some pro-apoptotic proteins as a result of these tumor-associated factors, interact with the anti-apoptotic counterpart and cause the alterations observed in thymocyte differentiation and thymic morphogenesis.

One essential characteristic inherent to the immune response is that cytokines regulate numerous aspects of hematopoiesis and $\mathrm{T}$ cell response via activation of the Jak/Stat pathways. The activated Jak proteins phosphorylate and activate specific Stat transcription factors. In recent unpublished data from our laboratory, using thymuses of normal and tumor-bearing mice, we have observed that thymic involution present in the thymuses of tumor-bearing mice is associated with a down-regulation of crucial cytokines involved in thymocyte development. This cytokine down-regulation could be closely related to an atypical expression of the apoptosis-related transcription factors. In this regard, we compared the expression of Jak/Stat signaling pathways in thymuses from normal and tumor-bearing mice, and several changes were noted between thymocytes from both types of mice. Some of these changes, for example, were the relative down-regulation of mRNA of CBP, Ghr and Sp1 in thymuses of tumor-bearing mice when compared to those of normal mice. These molecules have been shown to function as transcription factors with specific effects on thymic $\mathrm{T}$ lymphocyte 
proliferation and homeostasis in vivo and also its degradation occurs early during apoptosis (68-70). Moreover, Pias1, another transcription factor downregulated in thymuses of tumorbearing mice has been shown to function as a novel activator of p53 (71). The tumor suppressor protein p53 functions as a transcription factor that activates genes controlling cell cycle arrest and apoptosis (72). In addition, thymuses of tumorbearing mice have shown a down-regulation of a number of genes important for cell cycle progression and apoptosis.

Although all the possible mechanisms leading to the thymic involution and impaired thymopoiesis present in our mammary tumor bearers are not completely elucidated, based on the data presented herein and our previous studies, the following hypothesis could be proposed: the D1-DMBA-3 mouse mammary adenocarcinoma directly produces factors (collectively termed tumor-associated factors) which exert their influence directly, not only on immune related cells, but also on the stromal cell in the thymic microenvironment to produce an abnormal array of cytokines. These atypical levels of cytokines exert an opposing effect directly on the normal expression of the transcription factors which in turn regulates important cellular mechanisms such as cell cycle and apoptosis causing the observed thymic involution in tumor-bearing mice.

\section{Acknowledgements}

This research was supported by National Institutes of Health Grant RO1 CA25583.

\section{References}

1. Miller JF: Effect of thymectomy in adult mice on immunological responsiveness. Nature 208: 1337-1338, 1965

2. Haynes BF, Sempowski GD, Wells AF and Hale LP: The human thymus during aging. Immunol Res 22: 253-261, 2000.

3. Aspinall R: T cell development, ageing and Interleukin-7. Mech Ageing Dev 127: 572-578, 2006.

4. Scollay R, Wilson A, D'Amico A, et al: Developmental status and reconstitution potential of subpopulations of murine thymocytes. Immunol Rev 104: 81-120, 1988.

5. Godfrey DI, Kennedy J, Suda T and Zlotnik A: A developmental pathway involving four phenotypically and functionally distinct subsets of $\mathrm{CD} 3^{-} \mathrm{CD} 4^{-} \mathrm{CD} 8^{-}$triple-negative adult mouse thymocytes defined by CD44 and CD25 expression. J Immunol 150: 4244-4252, 1993.

6. Falk I and Eichmann K: Heterogeneity of the DN4 (CD44-CD25') subset of CD4-CD8 double negative thymocytes; dependence on CD3 signaling. Immunol Lett 82: 123-130, 2002.

7. Fehling HJ and von Boehmer H: Early alpha beta $\mathrm{T}$ cell development in the thymus of normal and genetically altered mice. Curr Opin Immunol 9: 263-275, 1997.

8. Borowski C, Martin C, Gounari F, et al: On the brink of becoming a T cell. Curr Opin Immunol 14: 200-206, 2002.

9. Yokosuka T, Sakata-Sogawa K, Kobayashi W, et al: Newly generated $\mathrm{T}$ cell receptor microclusters initiate and sustain $\mathrm{T}$ cell activation by recruitment of Zap70 and SLP-76. Nat Immunol 6: 1253-1262, 2005 .

10. Petrie HT, Livak F, Schatz DG, Strasser A, Crispe IN and Shortman K: Multiple rearrangements in T cell receptor alpha chain genes maximize the production of useful thymocytes. J Exp Med 178: 615-622, 1993.

11. Shortman K, Egerton M, Spangrude GJ and Scollay R: The generation and fate of thymocytes. Semin Immunol 2: 3-12, 1990.

12. Baumann S, Krueger A, Kirchhoff S and Krammer PH: Regulation of $\mathrm{T}$ cell apoptosis during the immune response. Curr Mol Med 2: 257-272, 2002.

13. Surh CD and Sprent J: T-cell apoptosis detected in situ during positive and negative selection in the thymus. Nature 372 100-103, 1994
14. Zhang N, Hartig H, Dzhagalov I, Draper D and He YW: The role of apoptosis in the development and function of T lymphocytes. Cell Res 15: 749-769, 2005.

15. Nunez $\mathrm{G}$ and Clarke MF: The Bcl-2 family of proteins: regulators of cell death and survival. Trends Cell Biol 4: 399-403, 1994.

16. Chao DT and Korsmeyer SJ: BCL-2 family: regulators of cell death. Annu Rev Immunol 16: 395-419, 1998.

17. Vaux DL, Cory S and Adams JM: Bcl-2 gene promotes haemopoietic cell survival and cooperates with c-myc to immortalize pre-B cells. Nature 335: 440-442, 1988.

18. Boise LH, Gonzalez-Garcia M, Postema CE, et al: bcl-X, a bcl-2-related gene that functions as a dominant regulator of apoptotic cell death. Cell 74: 597-608, 1993.

19. Kozopas KM, Yang T, Buchan HL, Zhou P and Craig RW: MCL1, a gene expressed in programmed myeloid cell differentiation, has sequence similarity to BCL2. Proc Natl Acad Sci USA 90: 3516-3520, 1993.

20. Lin EY, Orlofsky A, Berger MS and Prystowsky MB: Characterization of A1, a novel hemopoietic-specific early-response gene with sequence similarity to bcl-2. J Immunol 151: 1979-1988, 1993.

21. Oltvai ZN, Milliman CL and Korsmeyer SJ: Bcl-2 heterodimerizes in vivo with a conserved homolog, Bax, that accelerates programmed cell death. Cell 74: 609-619, 1993.

22. Chittenden T, Harrington EA, O'Connor R, et al: Induction of apoptosis by the Bcl-2 homologue Bak. Nature 374: 733-736, 1995.

23. Yang E, Zha J, Jockel J, Boise LH, Thompson CB and Korsmeyer SJ: Bad, a heterodimeric partner for Bcl-XL and Bcl-2, displaces Bax and promotes cell death. Cell 80: 285-291, 1995.

24. Boyd JM, Gallo GJ, Elangovan B, et al: Bik, a novel deathinducing protein shares a distinct sequence motif with Bcl-2 family proteins and interacts with viral and cellular survivalpromoting proteins. Oncogene 11: 1921-1928, 1995.

25. Wang K, Yin XM, Chao DT, Milliman CL and Korsmeyer SJ: BID: a novel BH3 domain-only death agonist. Genes Dev 10: 2859-2869, 1996.

26. Gibson L, Holmgreen SP, Huang DC, et al: bcl-w, a novel member of the bcl-2 family, promotes cell survival. Oncogene 13: 665-675, 1996.

27. Inohara N, Ding L, Chen S and Nunez G: Harakiri, a novel regulator of cell death, encodes a protein that activates apoptosis and interacts selectively with survival-promoting proteins Bcl-2 and Bcl-X(L). EMBO J 16: 1686-1694, 1997.

28. Inohara N, Ekhterae D, Garcia I, et al: Mtd, a novel Bcl-2 family member activates apoptosis in the absence of heterodimerization with Bcl-2 and Bcl-XL. J Biol Chem 273: 8705-8710, 1998.

29. Inohara N, Gourley TS, Carrio R, et al: Diva, a Bcl-2 homologue that binds directly to Apaf-1 and induces BH3-independent cell death. J Biol Chem 273: 32479-32486, 1998

30. Yu J, Zhang L, Hwang PM, Kinzler KW and Vogelstein B: PUMA induces the rapid apoptosis of colorectal cancer cells. Mol Cell 7: 673-682, 2001.

31. Gottschalk AR, Boise LH, Oltvai ZN, et al: The ability of $\mathrm{Bcl}-\mathrm{X}(\mathrm{L})$ and $\mathrm{Bcl}-2$ to prevent apoptosis can be differentially regulated. Cell Death Differ 3: 113-118, 1996.

32. Kim R: Unknotting the roles of Bcl-2 and Bcl-XL in cell death. Biochem Biophys Res Commun 333: 336-343, 2005.

33. Veis DJ, Sorenson CM, Shutter JR and Korsmeyer SJ: Bcl-2deficient mice demonstrate fulminant lymphoid apoptosis, polycystic kidneys, and hypopigmented hair. Cell 75: 229-240, 1993.

34. Nakayama K, Nakayama K, Negishi I, et al: Disappearance of the lymphoid system in Bcl-2 homozygous mutant chimeric mice. Science 261: 1584-1588, 1993.

35. Lopez-Hoyos M, Carrio R, Merino J and Merino R: Regulation of $\mathrm{B}$ cell apoptosis by $\mathrm{Bcl}-2$ and $\mathrm{Bcl}-\mathrm{XL}$ and its role in the development of autoimmune diseases (Review). Int J Mol Med 1: 475-483, 1998 .

36. Grillot DA, Merino R and Nunez G: Bcl-XL displays restricted distribution during $\mathrm{T}$ cell development and inhibits multiple forms of apoptosis but not clonal deletion in transgenic mice. J Exp Med 182: 1973-1983, 1995.

37. Chao DT and Korsmeyer SJ: BCL-XL-regulated apoptosis in T cell development. Int Immunol 9: 1375-1384, 1997.

38. Tomayko MM, Punt JA, Bolcavage JM, Levy SL, Allman DM and Cancro MP: Expression of the Bcl-2 family member A1 is developmentally regulated in T cells. Int Immunol 11: 1753-1761, 1999. 
39. Verschelde C, Michonneau D, Trescol-Biemont MC, Berberich I, Schimpl A and Bonnefoy-Berard N: Overexpression of the antiapoptotic protein A1 promotes the survival of double positive thymocytes awaiting positive selection. Cell Death Differ 13: 1213-1221, 2006

40. Aspinall $\mathrm{R}$ and Andrew D: Thymic involution in aging. J Clin Immunol 20: 250-256, 2000.

41. Linton PJ and Dorshkind K: Age-related changes in lymphocyte development and function. Nat Immunol 5: 133-139, 2004.

42. Taub DD and Longo DL: Insights into thymic aging and regeneration. Immunol Rev 205: 72-93, 2005.

43. Medina D and De Ome KB: Response of hyperplastic alveolar nodule outgrowth-line D1 to mammary tumor virus, noduleinducing virus, and prolonged hormonal stimulation acting singly and in combination. J Natl Cancer Inst 42: 303-310, 1969.

44. Fu YX, Altman N and Lopez DM: Thymic atrophy induced by murine mammary adenocarcinoma in vivo. In Vivo 3: 1-5, 1989.

45. Fu Y, Paul RD, Wang Y and Lopez DM: Thymic involution and thymocyte phenotypic alterations induced by murine mammary adenocarcinomas. J Immunol 143: 4300-4307, 1989.

46. Adkins B, Charyulu V, Sun QL, Lobo D and Lopez DM: Early block in maturation is associated with thymic involution in mammary tumor-bearing mice. J Immunol 164: 5635-5640, 2000.

47. Carrio R, Lopez-Hoyos M, Jimeno J, et al: A1 demonstrates restricted tissue distribution during embryonic development and functions to protect against cell death. Am J Pathol 149: 2133-2142, 1996.

48. Carrio R, Bathe OF and Malek TR: Initial antigen encounter programs $\mathrm{CD}^{+} \mathrm{T}$ cells competent to develop into memory cells that are activated in an antigen-free, IL-7- and IL-15-rich environment. J Immunol 172: 7315-7323, 2004.

49. Boise LH, Minn AJ, Noel PJ, et al: CD28 costimulation can promote $\mathrm{T}$ cell survival by enhancing the expression of Bcl-XL. Immunity 3: 87-98, 1995.

50. Moore NC, Anderson G, Williams GT, Owen JJ and Jenkinson EJ: Developmental regulation of bcl-2 expression in the thymus. Immunology 81: 115-119, 1994.

51. Ciofani $\mathrm{M}$ and Zuniga-Pflucker JC: The thymus as an inductive site for T lymphopoiesis. Annu Rev Cell Dev Biol 23: 463-493, 2007.

52. Nowell CS, Farley AM and Blackburn CC: Thymus organogenesis and development of the thymic stroma. Methods Mol Biol 380: 125-162, 2007

53. Anderson G, Moore NC, Owen JJ and Jenkinson EJ: Cellular interactions in thymocyte development. Annu Rev Immunol 14: 73-99, 1996

54. Giovannetti A, Pierdominici M, Di Iorio A, et al: Apoptosis in the homeostasis of the immune system and in human immune mediated diseases. Curr Pharm Des 14: 253-268, 2008.

55. Gonzalez-Garcia M, Perez-Ballestero R, Ding L, et al: bcl-XL is the major bcl-X mRNA form expressed during murine development and its product localizes to mitochondria. Development 120: 3033-3042, 1994
56. Motoyama N, Wang F, Roth KA, et al: Massive cell death of immature hematopoietic cells and neurons in Bcl-x-deficient mice. Science 267: 1506-1510, 1995.

57. Orlofsky A, Berger MS and Prystowsky MB: Novel expression pattern of a new member of the MIP-1 family of cytokine-like genes. Cell Regul 2: 403-412, 1991.

58. Lin EY, Orlofsky A, Wang HG, Reed JC and Prystowsky MB: A1, a Bcl-2 family member, prolongs cell survival and permits myeloid differentiation. Blood 87: 983-992, 1996.

59. Williams GT and Smith CA: Molecular regulation of apoptosis: genetic controls on cell death. Cell 74: 777-779, 1993.

60. Sedlak TW, Oltvai ZN, Yang E, et al: Multiple Bcl-2 family members demonstrate selective dimerizations with Bax. Proc Natl Acad Sci USA 92: 7834-7838, 1995.

61. Yang E and Korsmeyer SJ: Molecular thanatopsis: a discourse on the BCL2 family and cell death. Blood 88: 386-401, 1996

62. Simonian PL, Grillot DA, Merino R and Nunez G: Bax can antagonize $\mathrm{Bcl}-\mathrm{XL}$ during etoposide and cisplatin-induced cell death independently of its heterodimerization with Bcl-XL. J Biol Chem 271: 22764-22772, 1996.

63. Watson GA, Fu YX and Lopez DM: Splenic macrophages from tumor-bearing mice co-expressing MAC-1 and MAC-2 antigens exert immunoregulatory functions via two distinct mechanisms. J Leukoc Biol 49: 126-138, 1991.

64. Fu YX, Watson G, Jimenez JJ, Wang Y and Lopez DM: Expansion of immunoregulatory macrophages by granulocytemacrophage colony-stimulating factor derived from a murine mammary tumor. Cancer Res 50: 227-234, 1990.

65. Lopez DM, Lopez-Cepero M, Watson GA, Ganju A, Sotomayor E and Fu YX: Modulation of the immune system by mammary tumor-derived factors. Cancer Invest 9: 643-653, 1991.

66. Calderon C, Huang ZH, Gage DA, Sotomayor EM and Lopez DM: Isolation of a nitric oxide inhibitor from mammary tumor cells and its characterization as phosphatidyl serine. J Exp Med 180: 945-958, 1994

67. Owen JL, Iragavarapu-Charyulu V, Gunja-Smith Z, Herbert LM, Grosso JF and Lopez DM: Up-regulation of matrix metalloproteinase-9 in T lymphocytes of mammary tumor bearers: role of vascular endothelial growth factor. J Immunol 171: 4340-4351, 2003.

68. Piedrafita FJ and Pfahl M: Retinoid-induced apoptosis and Sp1 cleavage occur independently of transcription and require caspase activation. Mol Cell Biol 17: 6348-6358, 1997.

69. Lanning NJ and Carter-Su C: Recent advances in growth hormone signaling. Rev Endocr Metab Disord 7: 225-235, 2006.

70. Baumann S, Kyewski B, Bleckmann SC, et al: CREB function is required for normal thymic cellularity and post-irradiation recovery. Eur J Immunol 34: 1961-1971, 2004.

71. Megidish T, Xu JH and Xu CW: Activation of p53 by protein inhibitor of activated Stat1 (PIAS1). J Biol Chem 277: 8255-8259, 2002.

72. Lane DP: Cancer. p53, guardian of the genome. Nature 358: 15-16, 1992. 